\title{
A reduction in milking frequency and feed allowance improves dairy cow immune status
}

\author{
K. O’Driscoll, ${ }^{1}{ }^{1}$ G. Olmos,† S. Llamas Moya,‡ J. F. Mee,§ B. Earley, ${ }^{\star}$ D. Gleeson,\# B. O’Brien,\# and L. Boylell \\ ${ }^{*}$ Animal and Bioscience Research Department, Animal and Grassland Research and Innovation Centre, Teagasc, Grange, Dunsany, Co. Meath, \\ Ireland \\ †The Royal Veterinary College, Hawkshead Lane, North Mymms, Hatfield, Hertfordshire, AL9 7TA, United Kingdom \\ ¥Kerry Ingredients and Flavours, Veluwezoom 62, 1327 AH Almere, the Netherlands \\ $\S$ Animal and Bioscience Research Department, \\ \#Livestock Systems Department, and \\ IIPig Development Department, Animal and Grassland Research and Innovation Centre, Teagasc, Moorepark, Fermoy, Co. Cork, Ireland
}

\begin{abstract}
Twice-daily milking is the most common milking regimen used globally. A reduction in milking frequency to once daily, combined with a reduced feed allowance (FA), could reduce the physiological stress associated with the transition to peak milk production, and hence improve immune function. This study investigated how milking frequency and FA affect dairy cow immune status. Cows $(\mathrm{n}=48)$ were milked once a day $(\mathrm{OAD})$ or twice a day (TAD) on 1 of 2 FA: high (HFA) or low (LFA), in a $2 \times 2$ factorial arrangement of treatments. After the mean calving date of March 11, HFA cows were offered ad libitum grass silage and $7 \mathrm{~kg}$ of concentrates/cow per day until March 22, then $4 \mathrm{~kg}$ of concentrates/cow per day until April 17, and thereafter allocated $31.3 \mathrm{~kg}$ of dry matter (DM) grass $/$ cow per day. The LFA cows were offered $4 \mathrm{~kg}$ of concentrates/ cow per day, $1 \mathrm{~kg}$ of concentrates/cow per day, and allocated $19 \mathrm{~kg}$ of DM grass/cow per day for the same respective periods. Milk yield was recorded daily and body condition score weekly, and somatic cell count was performed at approximately 2 -wk intervals. Blood samples were collected prepartum ( $\mathrm{d}-7$ to -1$)$ and at d 1 to 7 , d 14 to 21, and d 42 to 49 postpartum. Total and differential leukocyte percentage, IFN- $\gamma$ production in response to concanavalin A and phytohemagglutinin, and cortisol, haptoglobin (Hp), and serum amyloid A (SAA) concentrations were evaluated. Cows milked OAD had reduced milk yield and body reserve mobilization, but higher somatic cell counts. Milking frequency and diet had no effect on total leukocyte counts. Cows milked OAD had a higher lymphocyte percentage and lower monocyte percentage, and tended to have a lower neutrophil percentage than cows milked TAD. In addi-
\end{abstract}

Received March 31, 2011.

Accepted October 28, 2011.

${ }^{1}$ Corresponding author: keelin.odriscoll@teagasc.ie tion, the LFA cows had a higher eosinophil percentage than cows fed the HFA. Milking frequency and diet had no effect on IFN- $\gamma$, Hp, SAA, or cortisol production. Utilization of strategies to reduce milk yield at the beginning of the lactation could not only reduce body reserve mobilization, but also help to maintain a functioning immune system, and thus improve cow welfare. Key words: dairy cow, immune, milking frequency, nutrition

\section{INTRODUCTION}

Adjustments in hormone profiles and the physical and metabolic stress of calving and commencement of lactation alter immune function in dairy cows (Burton et al., 2005) and can lead to increased susceptibility to disease (Mallard et al., 1998). The adoption of practices that could ameliorate the stresses associated with the transition to milk production and up to peak lactation when milk yield is increasing warrants investigation.

An increase in blood concentration of the endogenous glucocorticoid cortisol in the peripartum period causes neutrophilia (Burton et al., 2005) and reduces the numbers of other classes of immune cells such as monocytes and lymphocytes (Fauci and Dale, 1974), all of which are signs of impaired immune function. The innate immune response elicited during this period is characterized by an increase in acute phase protein concentrations (Cairoli et al., 2006). This immunosuppression profile has been characterized in cows milked twice or 3 times daily, but it is unknown whether the profile is similar in cows milked at a lower frequency.

A reduction in milking frequency in early lactation reduces milk yield and consequently improves energy balance and metabolic status (McNamara et al., 2008; Schlamberger et al., 2010). Body condition score is improved (Davis et al., 1999; O'Brien et al., 2005) and concentrations of the blood metabolites NEFA and BHBA are reduced (Loiselle et al., 2009). Cows in nega- 
tive energy balance (NEB) have impaired leukocyte function (Suriyasathaporn et al., 2000); both NEFA and BHBA exhibit negative effects on leukocytes, such as decreased respiratory burst activity (Hoeben et al., 2000 ) and reduced secretion of IFN- $\gamma$ (Lacetera et al., 2005). Loiselle et al. (2009) also found that the peripheral blood mononuclear cells (PBMC) of cows milked once daily for just the first week postpartum had higher IFN- $\gamma$ secretion at 5 and $14 \mathrm{~d}$ in milk than cows milked twice daily from the start of lactation. Loiselle et al. (2009) also concluded that immunosuppression in early lactation is primarily due to the metabolic changes that occur at this time. Moreover, Hiss et al. (2009) found higher serum haptoglobin $(\mathbf{H p})$ levels in cows with high levels of BHBA and NEFA during the peripartum period. Thus, milking cows once daily, as a mechanism to reduce NEB, could help improve dairy cow immune function at this time.

However, some evidence exists that reducing milking frequency can cause neutrophilia (Keane, 2004) as well as reduced neutrophil and monocyte functionality (Llamas Moya et al., 2008). Llamas Moya et al. (2008) suggested that the reduced phagocytic activity of neutrophils in cows milked once a day (OAD) was due to stress arising from a higher level of udder distension compared with cows milked twice a day (TAD; Gleeson et al., 2007; O'Driscoll et al., 2010). However, although increased udder distension could increase stress in early lactation when milk yield is increasing, it appears the effects are transient (O'Driscoll et al., 2011) and therefore unlikely to negate the benefits associated with reduced NEB. Moreover, any negative effect of OAD milking could be reduced by decreasing the amount of feed offered. A high herbage allowance combined with concentrate supplementation not only increases milk production throughout lactation (Kennedy et al., 2007), but also increases udder firmness scores (Gleeson et al., 2007). It is thus possible that a reduction in feed allowance (FA) could help to reduce milk accumulation and consequently any discomfort experienced by OAD cows in early lactation.

The objectives of this study were to investigate the effect of milking cows OAD at $2 \mathrm{FA}$ on the following indicators of stress and immune status in dairy cows: concentration of cortisol, concentration of acute phase proteins (Hp and serum amyloid A, SAA), leukocyte count and percentage, and IFN- $\gamma$ concentration after production in response of $\mathrm{PBMC}$ to 2 mitogens, concanavalin A (Con A) and phytohemagglutinin (PHA). The proposed hypothesis was that OAD milking combined with a low FA would result in improved immune function in these cows compared with cows milked TAD or cows on a high FA.

\section{MATERIALS AND METHODS}

The study was conducted at Teagasc "Moorepark" research farm, which is part of the Animal and Grassland Research and Innovation Centre, Teagasc (Moorepark, Fermoy, Co. Cork, Ireland; $50^{\circ} 07^{\prime} \mathrm{N} ; 8^{\circ} 16^{\prime} \mathrm{W}$ ) between December 2005 and June 2006.

\section{Animals and Treatments}

Forty-eight spring-calving (mean calving date: March 11; range: February 13 to April 14) Holstein-Friesian primiparous $(\mathrm{n}=22)$ and multiparous cows $(\mathrm{n}=26$; parity range 3 to 8; parity mean 4.5) from the Animal and Grassland Research and Innovation Centre herd were used. Cows were assigned randomly after calving to 1 of 4 treatments in a $2 \times 2$ factorial arrangement of treatments consisting of OAD or TAD milking at a high FA (HFA) or low FA (LFA) $(n=12$ cows per treatment).

Postpartum, cows were housed in cubicles (freestalls) until March 22. During this time, cows were fed perennial grass silage (Lolium perenne) ad libitum. In addition, HFA cows received $7 \mathrm{~kg} / \mathrm{cow}$ per day of concentrates, whereas LFA cows received $4 \mathrm{~kg} / \mathrm{cow}$ per day of concentrates up to March 22, thus creating a difference in FA. Between March 23 and 29, inclusive, cows were at pasture by day only and housed in cubicles at night. They were offered perennial ryegrass (Lolium perenne) and grazing management was based on a rotational grazing system. The first grazing cycle took place between March 23 and April 17. During this period, HFA cows received $4 \mathrm{~kg} / \mathrm{d}$ of concentrate and LFA cows received $1 \mathrm{~kg} / \mathrm{d}$ of concentrate. Subsequent to April 17, the difference in feeding regimens was dictated by postgrazing sward height. A fixed land area was allocated to each treatment group giving a stocking rate of 2.7 and 3.9 cows/ha for HFA and LFA groups, respectively, for the duration of the grazing season. Each grazing block was subdivided into 11 paddocks, with cows remaining in each paddock for $3.3 \mathrm{~d}$ on average (from May 6 to Nov 1). All groups were allocated fresh grass once daily and moved to new grazing blocks at the same time. At least 30 grass measurements were taken using an electronic plate meter (Urban and Caudal, 1990) with a plastic plate $(30 \mathrm{~cm} \times 30 \mathrm{~cm}$ and $4.5 \mathrm{~kg} / \mathrm{m}$; Agrosystèmes, Choiselle, France) across each paddock before each grazing period to establish the pregrazing heights. In addition, 2 grass strips were harvested $(10 \times 15 \mathrm{~m})$ to a height of $4 \mathrm{~cm}$ to calculate the pregrazing yields in each paddock before grazing. Dry matter analysis was carried out on 4 grass samples taken per paddock, and 10 grass height measurements were recorded before and 
after harvesting on each cut strip using the plate meter. After each grazing period, at least 30 grass measurements were taken using the plate meter across each paddock to establish the postgrazing heights. Paddock measurements were conducted on 53 occasions and the average daily intake per cow was calculated based on stocking rate and grass measurements.

Cows on the HFA and LFA treatments grazed to a postgrazing sward height of 83 and $68 \mathrm{~mm}$, respectively. Stocking density was based on herbage allowance ( $\mathrm{kg}$ of $\mathrm{DM} / \mathrm{cow}$ ) calculated by taking account of the pregrazing herbage yield ( $\mathrm{kg}$ of $\mathrm{DM} / \mathrm{ha}$ ), size of paddock (ha), and number of cows. Herbage allowances were as follows: $\mathrm{HFA} \mathrm{TAD}=30.6$; $\mathrm{HFA} \mathrm{OAD}=32.0$; LFA $\mathrm{TAD}=19.4$; and LFA OAD $=18.6 \mathrm{~kg}$ of $\mathrm{DM}$ per cow/d, respectively. The actual amount of grass removed per cow/d in the groups was as follows: HFA $\mathrm{TAD}=19.3 ; \mathrm{HFA} \mathrm{OAD}=19.7 ; \mathrm{LFA} \mathrm{TAD}=14.6 ;$ and LFA OAD $=14.0 \mathrm{~kg}$ DM. Paddocks were topped by mechanical means to maintain pasture quality across treatments. The OAD cows were milked at $0730 \mathrm{~h}$, and the TAD cows were milked at 0730 and $1530 \mathrm{~h}$. All animal procedures were carried out under experimental license in accordance with the European Communities (Amendment of Cruelty to Animals Act, 1876) regulations 2002.

\section{Production Measurements}

Milk yield was measured at each milking for every cow using electronic milk meters (Dairymaster, Causeway, Co. Kerry, Ireland). Clusters removed automatically once milk flow decreased below $0.2 \mathrm{~kg} / \mathrm{min}$. Body condition score was recorded once weekly by a single observer on a scale of 1 to $5(1=$ emaciated, $5=$ extremely fat) with increments of 0.25 (Lowman et al., 1976). Individual cow milk samples were taken approximately every other week $(10.5 \pm 5.5 \mathrm{~d}$; mean \pm SD $)$ at one morning and one evening milking, and SCC was determined using the Bentley Somacount 200 (Bentley Instruments Inc., Chaska, MN). Milk samples were representative of the 4 quarters and the entire milking.

\section{Immune Measurements}

Two blood samples were collected from each cow by coccygeal venipuncture immediately after morning milking (approximately $0830 \mathrm{~h}$ ) once during the following intervals: $7 \mathrm{~d}$ before calving $(7 \pm 3.8$; mean $\pm \mathrm{SD}$ : prepartum sample), and d 1 to $7(5 \pm 2.2), 14$ to 21 $(16 \pm 2.4)$, and 42 to $49(45 \pm 2.2)$ postpartum. Blood samples were transported to the laboratory, stored at ambient temperature, and processed within $3.5 \mathrm{~h}$ for hematological analysis, including white blood count differentials and IFN- $\gamma$ production, or centrifuged, separated, and stored at $-20^{\circ} \mathrm{C}$ until cortisol and acute phase protein assays were performed.

Cortisol and Acute Phase Proteins. Blood collected into a 9-mL lithium heparinized tube (Vacutainer, Unitech Ltd., Dublin, Ireland) was used for measurement of cortisol, Hp, and SAA concentrations. Blood tubes were centrifuged at 2,000 $\times g$ for 10 min at $5^{\circ} \mathrm{C}$, and then plasma was aspirated using a pipette into 3 screw-top glass vials and stored at $-20^{\circ} \mathrm{C}$ until analysis. Plasma cortisol concentration was measured using an ELISA (DRG-Diagnostics, Marburg, Germany). The sensitivity of the assay was $1.14 \mathrm{ng} / \mathrm{mL}$, and the intra- and interassay CV based on controls were $<2.8$ and $<5.5 \%$, respectively.

Plasma Hp concentration was measured using the Tridelta phase range Haptoglobin ELISA kit (Tridelta, Maynooth, Co Kildare, Ireland). The sensitivity of the assay was $0.05 \mathrm{~g} / \mathrm{L}$, and the intra- and interassay CV based on controls were $<2.5$ and $<3.0 \%$, respectively.

Plasma SAA concentration was measured using the Tridelta phase range SAA kit, a solid-phase sandwich ELISA (Tridelta). The minimum detectable concentration of SAA was $0.3 \mathrm{mg} / \mathrm{L}$, and the intra- and interassay $\mathrm{CV}$ based on controls were $<3.0$ and $<5.6 \%$, respectively. All ELISA-based kits were used in accordance with the manufacturer's instructions.

Hematology. Blood was collected into EDTAanticoagulated 6-mL blood tubes (Vacutainer, Unitech Ltd.). Total leukocyte count was measured using a hematology analyzer (Celltac MEK-610K, Nihon Kohden Corp., Tokyo, Japan), and a differential cell count (neutrophil, lymphocyte, monocyte, eosinophil, and basophil percentages) manually counted using the Giemsa stain technique. One hundred cells were counted for each cow at each blood sampling time point. Thin blood smears on grease-free glass slides (Goldstar micro slides, Chance Propper, Leicester, UK) were prepared, air-dried, and stained using the hematology 3-step stains for differentiation of morphological cell types (Accralab, Fisher Scientific Co., Middleton, VA). One hundred cells, including neutrophils, band neutrophils, basophils, eosinophils, monocytes, and lymphocytes were counted under the microscope at $40 \times$ magnification.

IFN- $\gamma$ Production. In vitro lymphocyte IFN- $\gamma$ production was determined in whole blood cultures following the procedures described in Ting et al. (2003). The IFN- $\gamma$ production in response to novel challenges with Con $\mathrm{A}$ and PHA were quantified in vitro using an enzyme immunoassay. Blood was collected into a 9-mL lithium-heparinized tube (Vacutainer, Unitech Ltd.). Duplicate $1.48-\mathrm{mL}$ aliquots of blood were cultured in 24-well culture plates (Costar Corporation, Cambridge, 
MA) with $20 \mu \mathrm{L}$ of PBS containing $1.0 \mathrm{mg} / \mathrm{mL}$ of PHA, $1.0 \mathrm{mg} / \mathrm{mL}$ of Con A, or no additive (i.e., 6 wells were used per animal at each sampling date, 2 each for PHA, Con A, and PBS) for $16 \mathrm{~h}$ at $37^{\circ} \mathrm{C}$ and in an atmosphere of $5 \% \mathrm{CO}_{2}$ in air. The culture plates were centrifuged and the plasma harvested and stored at $-20^{\circ} \mathrm{C}$ until assayed for IFN- $\gamma$ production by lymphocytes using an ELISA (BOVIGAM, Biocor Animal Health, Omaha, NE), as described previously (Rothel et al., 1990). The in vitro PHA- and Con A-stimulated IFN- $\gamma$ production was calculated by subtracting the optical density (OD) at $450 \mathrm{~nm}$ of wells that received PBS alone from the absorbency of wells that received either PHA or Con A.

\section{Statistical Analyses}

Statistical analyses were carried out using SAS version 9.1 (2002; SAS Institute Inc., Cary, NC). All data were tested for normality before analysis by examination of box and normal distribution plots, and then transformed where necessary. A $\log _{2}$ transformation of SCC to SCS was used to normalize the data distribution. Data including milk yield, BCS, and SCS, but excluding monocyte, basophil, and eosinophil percentages, were analyzed $(2 \times 2$ factorial arrangement of treatments) using the Mixed procedure. The model included fixed effects of parity group (primiparous or multiparous), milking frequency (TAD or OAD), FA (HFA or LFA), and either sampling day (for immune measures; d 1 to 7 , d 14 to 21 , or d 42 to 49 postpartum) or sampling week (for milk yield and SCC; wk 1 to 7 ), as well as all possible 2 -way interactions. The prepartum sample ( $\mathrm{d}-7$ to -1 ) was used as a covariate for immune measures, and calving date was used as a covariate for milk yield and SCC. The repeated statement was used to take repeated measures for each individual animal into account. The change in BCS between calving and wk 7 was calculated for each cow, and the data were analyzed using a similar model as before but without the repeated statement and effect of time included. When significant effects were found, Tukey's test was used to establish pair-wise differences. Statistical differences were considered significant at $P \leq$ 0.05 . Tendencies toward significance $(0.05<P<0.10)$ are also presented. Data are presented as least squares means \pm standard errors. Model fit was determined in all analyses by choosing models with the minimum finite-sample corrected Akaike information criterion (AIC). The Wilcoxon rank test was used to investigate pair-wise differences in monocyte, basophil, and eosinophil percentages between milking frequency, FA, and parity status at each sampling day. These percentages are reported as means and interquartile ranges.

\section{RESULTS}

\section{Effect of Milking Frequency and FA}

Both milking frequency and FA $(P<0.01)$ had an effect on milk yield during the first $49 \mathrm{~d}$ of lactation. Cows milked TAD produced $157.8 \pm 4.2 \mathrm{~kg} /$ wk (average total over $49 \mathrm{~d}=1,142 \mathrm{~kg}$ ), compared with 125.3 $\pm 4.1 \mathrm{~kg} /$ wk by cows milked OAD (average total over $49 \mathrm{~d}=885 \mathrm{~kg} ; P<0.001)$. Likewise, cows on HFA produced $149.4 \pm 4.1 \mathrm{~kg} /$ wk (average total over $49 \mathrm{~d}$ $=1,064 \mathrm{~kg}$ ) compared with $125.3 \pm 4.1 \mathrm{~kg} /$ wk by cows on the low FA (average total over $49 \mathrm{~d}=954 \mathrm{~kg} ; P$ $<0.01)$. We observed an interaction between milking frequency and FA $(P<0.05)$. When cows were milked OAD, average weekly yield of cows on HFA (126.4 \pm $5.4 \mathrm{~kg})$ or LFA $(124.3 \pm 5.9 \mathrm{~kg})$ did not differ. However, cows milked TAD produced more milk on HFA $(172.4 \pm 5.9 \mathrm{~kg})$ than on LFA $(143.2 \pm 5.6 \mathrm{~kg} ; P<$ 0.01). Moreover, cows milked TAD on HFA produced more milk than OAD cows on either HFA or LFA $(P<$ 0.001 for both), whereas cows milked TAD on LFA only tended to produce more milk than OAD cows on HFA $(P=0.1)$ and LFA $(P=0.09)$.

Cows milked TAD lost more body condition between the first examination $(4.4 \pm 1.8 \mathrm{~d}$ postpartum) and last examination $(46.4 \pm 1.8 \mathrm{~d}$ postpartum; $0.57 \pm 0.10)$ compared with cows milked OAD $(0.23 \pm 0.10 ; P<$ $0.05)$, but FA had no effect. Cows milked OAD had a higher SCS $(17.2 \pm 0.2)$ than TAD cows $(16.3 \pm 0.2 ; P$ $<0.01$ ), but FA had no effect on SCS.

Neither milking frequency nor FA had an effect on cortisol, SAA, or Hp concentrations or on total leukocyte count. However, cows milked OAD tended to have lower neutrophil percentage than TAD cows (Table 1; $P=0.09)$. We found an interaction between milking frequency and FA for neutrophil percentage (Figure $1 \mathrm{~A} ; P<0.05)$. The OAD cows on HFA had a lower neutrophil percentage than TAD cows on HFA $(P<$ $0.05)$, whereas neutrophil percentage did not differ between OAD and TAD cows on LFA. The TAD cows on HFA also tended $(P=0.07)$ to have a higher neutrophil percentage than TAD cows on LFA. We found a tendency for an interaction between parity group and milking frequency for neutrophil percentage $(P=0.08)$. Neutrophil percentage did not differ for primiparous cows that were milked once $(36.6 \pm 2.0)$ or twice $(36.3$ \pm 2.1 ), but TAD multiparous cows milked tended to have higher neutrophil percentage $(42.6 \pm 1.9)$ than OAD multiparous cows $(35.5 \pm 2.0 ; P=0.06)$.

Cows milked OAD had a higher lymphocyte percentage than TAD cows (Table 1; $P<0.05$ ). A tendency for an interaction was found between milking frequency and FA for lymphocyte percentage (Figure 1B; $P=$ 
Table 1. Effect of milking frequency, feed allowance, and parity group on neutrophil and lymphocyte percentage $^{1}$

\begin{tabular}{|c|c|c|}
\hline Item & $\begin{array}{c}\text { Neutrophil } \\
(\%)\end{array}$ & $\begin{array}{c}\text { Lymphocyte } \\
(\%)\end{array}$ \\
\hline \multicolumn{3}{|c|}{ Milking frequency } \\
\hline Once & $36.05 \pm 1.40$ & $60.70 \pm 1.43$ \\
\hline Twice & $39.45 \pm 1.40$ & $56.55 \pm 1.41$ \\
\hline$P$-value & 0.09 & 0.04 \\
\hline \multicolumn{3}{|l|}{ Feed allowance } \\
\hline High & $38.93 \pm 1.47$ & $57.53 \pm 1.49$ \\
\hline Low & $36.58 \pm 1.49$ & $59.72 \pm 1.34$ \\
\hline$P$-value & 0.24 & 0.28 \\
\hline \multicolumn{3}{|l|}{ Parity } \\
\hline Primiparous & $36.45 \pm 1.46$ & $60.42 \pm 1.48$ \\
\hline Multiparous & $39.05 \pm 1.34$ & $56.83 \pm 1.36$ \\
\hline$P$-value & 0.20 & 0.08 \\
\hline
\end{tabular}

${ }^{1}$ The values are expressed as LSM $\pm \mathrm{SE}$ and calculated using all sampling times.

\section{A}

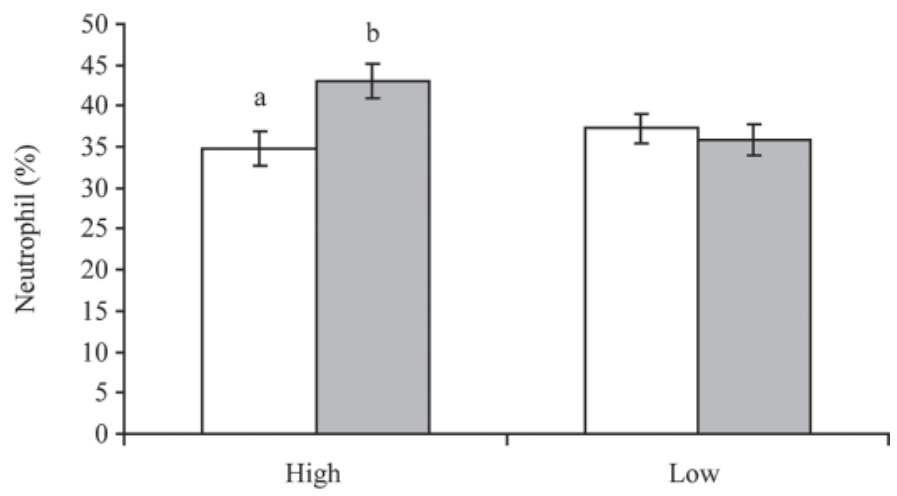

B

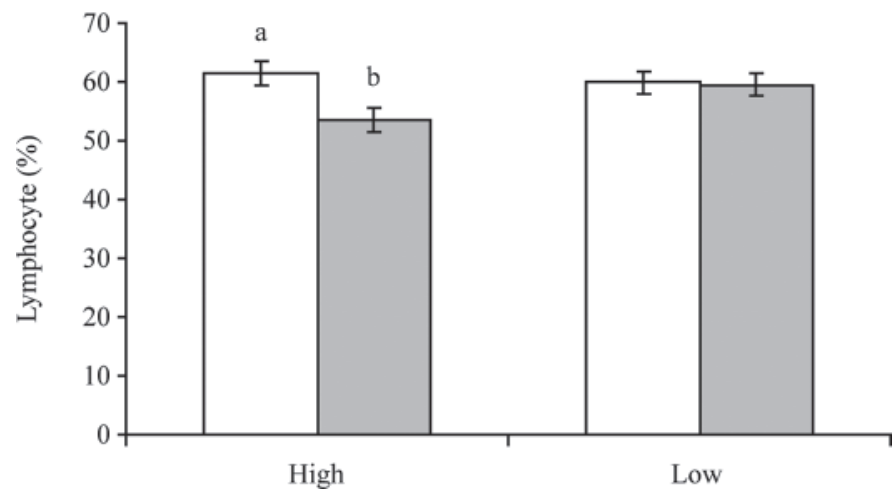

Figure 1. (A) Neutrophil percentage and (B) lymphocyte percentage of cows milked either once or twice daily at a high or low feed allowance; an interaction was found between milking frequency and feed allowance $(P<0.05)$ for neutrophil percentage, and a tendency for an interaction was found between milking frequency and feed allowance $(P=0.07)$ for lymphocyte percentage. Letters indicate significant differences at $P \leq 0.05$. Neutrophil and lymphocyte percentages at $d-7$ to -1 were used as covariates in the respective analyses. Error bars indicate standard errors.
0.07). Cows milked OAD on HFA had a higher lymphocyte percentage than cows milked TAD on HFA $(P=$ 0.05). Moreover, cows milked OAD on LFA tended to have a higher lymphocyte percentage than cows milked TAD on HFA $(P=0.1)$. Milking frequency and FA had no effect on basophil percentage, and milking frequency had no effect on eosinophil percentage. However cows on the HFA had a lower eosinophil percentage (range in parentheses) $[2.7(0-4)]$ than cows on the LFA [3.36 $(1-5) ; P=0.05]$ overall, and at 1 to $7 \mathrm{~d}(P=0.09)$ and 14 to $21 \mathrm{~d}(P=0.1)$. Cows milked OAD had a lower monocyte percentage $[0.24(0-0)]$ than TAD cows $[0.49$ $(0-1) ; P<0.05$; Figure 2], but FA had no effect.

Milking frequency or FA had no effect on IFN- $\gamma$ production in response to ConA or PHA. However, a tendency for an interaction was observed between milking frequency and FA on IFN- $\gamma$ production in response to Con A $(P=0.07$; Figure 3$)$.

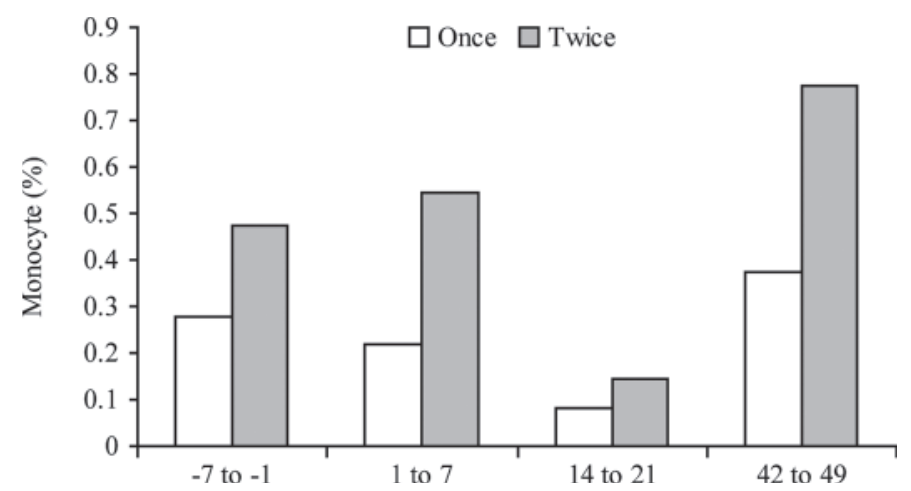

Figure 2. Monocyte percentage of cows milked once or twice daily at d 1 to $7, \mathrm{~d} 14$ to 21 , and d 42 to 49 postpartum. Milking frequency $(P<0.05)$ and sampling day $(P<0.01)$ affected monocyte percentage. 


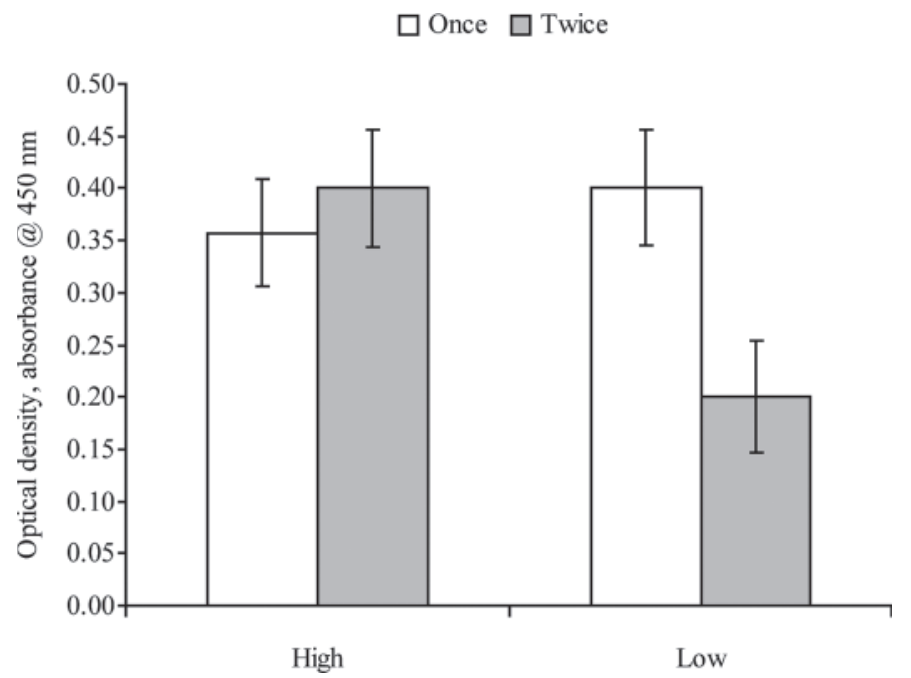

Figure 3. Interferon- $\gamma$ production after in vitro stimulation of blood with concanavalin A (optical density, absorbance at $450 \mathrm{~nm}$ ) of cows milked once or twice daily at a high or low feed allowance. A tendency for an interaction was found between milking frequency and feed allowance on IFN- $\gamma$ production $(P=0.07)$. Error bars indicate standard errors.

\section{Effect of Parity}

Multiparous cows had higher average weekly milk yields $(173.7 \pm 3.9 \mathrm{~kg})$ than primiparous cows $(109.4$ $\pm 4.3 \mathrm{~kg} ; P<0.001)$. However, parity did not affect BCS or SCS. Parity group did not affect cortisol or SAA concentrations, but primiparous cows had higher serum Hp concentrations $(0.59 \pm 0.09 \mathrm{mg} / \mathrm{mL})$ than multiparous cows $(0.24 \pm 0.08 \mathrm{mg} / \mathrm{mL} ; P<0.05)$.

Parity had no effect on total leukocyte count, or on neutrophil, lymphocyte, basophil, or monocyte percentages. Multiparous cows had a higher eosinophil percentage $[4.1(1-6)]$ than primiparous cows $[1.8(0-3) ; P$ $<0.001]$ overall and on each sampling day.

The PBMC of multiparous cows produced more IFN- $\gamma(0.427 \pm 0.036 \mathrm{OD}$ at $450 \mathrm{~nm})$ than those of primiparous cows $(0.251 \pm 0.041 ; P<0.05)$ in response to Con A, but parity group did not affect IFN- $\gamma$ production in response to PHA.

\section{Effect of Sampling Day}

Milk production increased over time $(P<0.001)$ and SCS decreased $(P<0.001)$. Sampling day affected cortisol concentration $(P<0.001)$ : cortisol at $\mathrm{d} 14$ to 21 was lower $(6.15 \pm 0.42 \mathrm{ng} / \mathrm{mL})$ than at either $\mathrm{d} 1$ to $7(7.54 \pm 0.43 \mathrm{ng} / \mathrm{mL} ; P=0.01)$ or $d 42$ to $49(8.34 \pm$ $0.68 \mathrm{ng} / \mathrm{mL} ; P<0.01)$.

Sampling day did affect SAA concentration $(P<$ 0.01 ): SAA concentration at d 42 to 49 postpartum was lower $(10.1 \pm 4.4 \mu \mathrm{g} / \mathrm{mL})$ than at $\mathrm{d} 14$ to $21(21.5 \pm$ $3.8 \mu \mathrm{g} / \mathrm{mL} ; P<0.01)$ and at $\mathrm{d} 1$ to $7(23.1 \pm 3.7 \mu \mathrm{g} /$
$\mathrm{mL} ; P<0.01)$. A tendency for an interaction was found between parity group and sampling day $(P=0.09)$ on SAA concentration. Primiparous cows had numerically higher SAA concentrations at $\mathrm{d} 1$ to 7 postpartum (35.5 $1 \pm 5.4 \mu \mathrm{g} / \mathrm{mL}$ ) compared with multiparous cows (10.8 $1 \pm 5.1 \mu \mathrm{g} / \mathrm{mL}$ ), whereas values were similar at $\mathrm{d} 14$ to 21 (primiparous $=21.41 \pm 5.6 \mu \mathrm{g} / \mathrm{mL}$; multiparous $=$ $21.61 \pm 5.1 \mu \mathrm{g} / \mathrm{mL})$, and multiparous cows had higher values $(14.7 \pm 5.6 \mu \mathrm{g} / \mathrm{mL})$ than primiparous $(5.5 \pm 6.8$ $\mu \mathrm{g} / \mathrm{mL})$ at $\mathrm{d} 42$ to 49 .

Sampling day also had an effect $(P=0.01)$ on serum Hp concentration. Similar to SAA, Hp concentration was lower at d 42 to 49 postpartum $(0.18 \pm 0.10 \mathrm{mg} /$ $\mathrm{mL})$ than at $\mathrm{d} 14$ to $21(0.45 \pm 0.09 \mathrm{mg} / \mathrm{mL} ; P<$ $0.05)$ or $\mathrm{d} 1$ to 7 postpartum $(0.61 \pm 0.09 \mathrm{mg} / \mathrm{mL} ; P$ $<0.05)$. We observed an interaction between milking frequency and sampling day on $\mathrm{Hp}$ concentration $(P<$ 0.05; Figure 4).

Sampling day did not affect total leukocyte count, neutrophil percentage, or lymphocyte percentage. However, an interaction was found between parity group and sampling day for neutrophil percentage (Figure $5 \mathrm{~A} ; P<0.05$ ) and lymphocyte percentage (Figure 5B; $P<0.05)$. Sampling day had an effect on basophil $(P<$ $0.05)$ and eosinophil percentages $(P<0.001)$. Basophil percentage was lower at d 42 to $49[0.02(0-0)]$ than at d 14 to 21 [0.13 (0-0); $P<0.05]$, d 7 to 14 [0.20 $(0-0) ; P<0.01]$, or the prepartum sampling day [0.24 $(0-0) ; P<0.01]$, whereas eosinophil percentage was higher at d 42 to $49[5.87(2-8)]$ than at $d 14$ to 21 [1.64 (0 - 3); $P<0.001]$, d 7 to 14 [1.53 $(0-2) ; P<$ $0.001]$, or the prepartum sampling day [3 $(0-4) ; P<$ 0.001]. We also observed an effect of sampling day on monocyte percentage $(P<0.01)$. Monocyte percentage

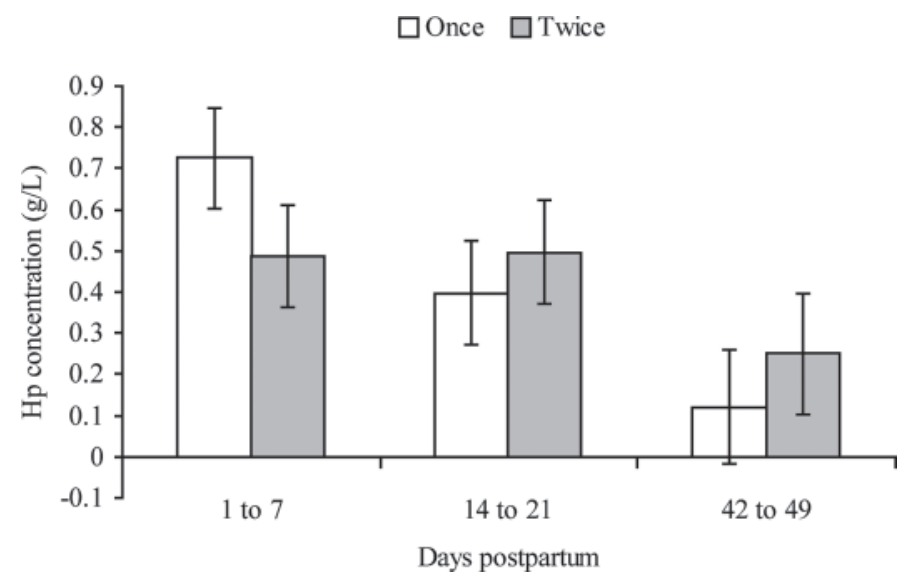

Figure 4. Plasma haptoglobin $(\mathrm{Hp})$ concentration in cows milked once or twice daily at d 1 to 7 , d 14 to 21 , and d 42 to 49 postpartum. The concentration of $\mathrm{Hp}$ at $\mathrm{d}-7$ to -1 was used as a covariate in the analysis. An effect of sampling day $(P=0.01)$ and an interaction between sampling day and milking frequency $(P<0.05)$ were found. Error bars indicate standard errors. 
A

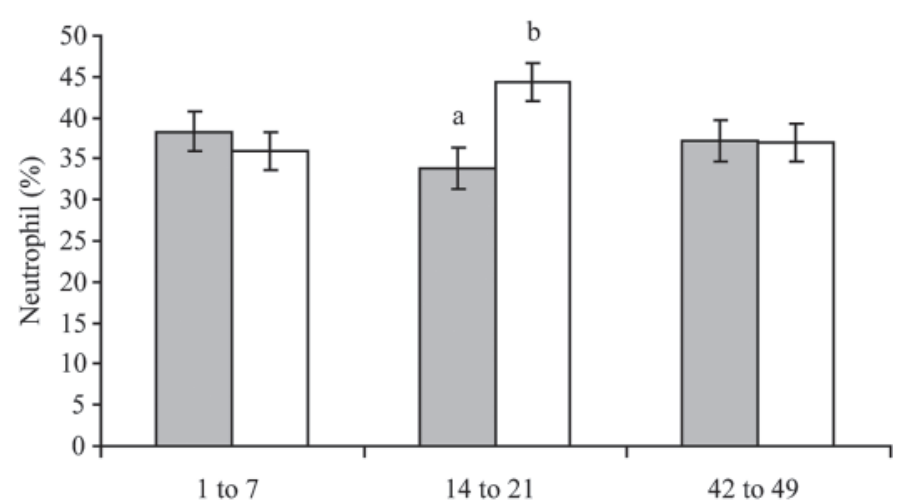

B

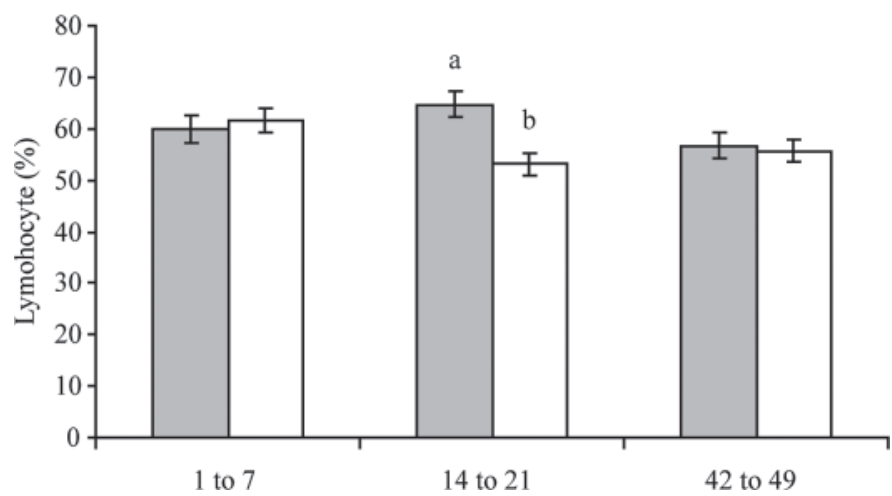

Figure 5. (A) Neutrophil percentage and (B) lymphocyte percentage of multiparous and primiparous cows at d 1 to $7, \mathrm{~d} 14$ to 21 , and d 42 to $49 \mathrm{~d}$ postpartum of multiparous and primiparous cows. An interaction was found between parity group and sampling day for neutrophil percentage $(P<0.05)$ and for lymphocyte percentage $(P<$ $0.05)$. Letters indicate significant differences at $P \leq 0.05$. Neutrophil and lymphocyte percentages at $\mathrm{d}-7$ to -1 were used as covariates in the respective analyses. Error bars indicate standard errors.

at d 14 to $21[0.11(0-0)]$ tended to be lower than at the prepartum sampling day $[0.38(0-0) ; P=0.09]$ and was lower than at d 42 to 49 [0.57 (0-1); $P<0.001]$. Monocyte percentage also tended to be higher at d 42 to 49 than at $\mathrm{d} 7$ to $14[0.38(0-0) ; P=0.06]$.

Sampling day affected $(P<0.001)$ IFN- $\gamma$ production in response to Con A; IFN- $\gamma$ production was lower at d 1 to $7(0.260 \pm 0.045)$ than at d 14 to $21(0.332 \pm$ $0.045 ; P<0.05)$ and $\mathrm{d} 42$ to $49(0.426 \pm 0.044 ; P<$ 0.001 ), and tended to be lower at $\mathrm{d} 14$ to 21 than at $\mathrm{d}$ 42 to $49(P=0.06)$. Sampling day did not affect IFN- $\gamma$ production in response to PHA.

\section{DISCUSSION}

Several measures of immune function were assessed in this study. Cows milked OAD tended to have a lower neutrophil percentage, and had a higher lymphocyte percentage compared with cows milked TAD, particularly when managed at the higher feed allowance.
Moreover, OAD cows had a lower monocyte percentage than TAD cows, and when cows were milked TAD, their PBMC produced less IFN- $\gamma$ when provided with an LFA than when provided with an HFA. However, for most of the other measures, milking frequency and feed allowance had no effect. Thus, our results only partially support the hypothesis that reducing metabolic stress at the beginning of the lactation by milking cows OAD would be associated with improvements in immune function.

Neither milking frequency nor feed allowance affected cortisol concentration. This finding concurs with the work of Tucker et al. (2007), who found no effect of a change in milking frequency on fecal glucocorticoid metabolite concentration later in the lactation, and also with Herskin et al. (2003), who found no effect of milking frequency (2 or 3 times daily) on plasma cortisol concentration. Keane et al. (2006) found that OAD cows had higher circulating cortisol concentrations than cows milked thrice daily. However, in that study, the cortisol concentrations of OAD cows were similar to those of both the TAD and OAD cows in our study (approximately 7.5 to $8 \mathrm{ng} / \mathrm{mL}$ ), whereas cortisol concentrations in cows milked thrice daily were much lower (approximately $4 \mathrm{ng} / \mathrm{mL}$ ), and the treatments did not differ by $28 \mathrm{~d}$ postpartum. The relative difference in udder pressure and discomfort between cows milked 3 times daily and once daily is likely to be much greater than that between cows milked twice versus once daily. Thus, the difference in cortisol concentration between cows milked once and 3 times daily is likely to be larger than between cows milked once and twice daily.

Sampling day was the only variable that had an effect on cortisol concentration. However, basal plasma cortisol concentrations were typical of values reported in the literature for dairy cows; that is, $<10 \mathrm{ng} / \mathrm{mL}$ (Venkataseshu and Estergreen, 1970; Thun et al., 1981). The major surge in cortisol concentration associated with parturition usually lasts $24 \mathrm{~h}$ (Patel et al., 1996; Madsen et al., 2002), which explains the high cortisol concentration immediately postpartum compared with the mean concentrations detected at the d 14 to 21 sampling point. Cortisol secretion also increases with stage of lactation, particularly up to peak lactation (Shayanfar et al., 1975), which accounts for the increase between d 14 to 21 and d 42 to 49. Our results indicate that any effect of once daily milking on dairy cow comfort and metabolic status at the beginning of the lactation is not enough to affect cortisol concentration, compared with twice daily milking.

Although we found no effect of milking frequency, feed allowance, or parity on cortisol concentration, these factors did have an effect on some of the immune measures recorded. As well as cortisol secretion, factors 
such as metabolic status can also have a negative effect on the functioning of leukocytes (Hoeben et al., 2000; Lacetera et al., 2004). In fact, previous studies have shown that endogenous cortisol secretion per se might not be responsible for impairment of immune function (e.g., following castration; Fisher et al., 1997a,b), which could explain why differences were detected in leukocyte differential in the absence of treatment differences in cortisol concentration.

Changes in leukocyte counts, as characterized by neutrophilia, lymphopenia, eosinopenia, and sometimes monocytosis, occur during periods of stress (Cole et al., 1997). Cows milked OAD had a lower neutrophil percentage, higher lymphocyte percentage, and lower monocyte percentage than cows milked TAD, which could be an indication of physiological stress. Moreover, cows milked TAD on the high nutrition diet had a higher neutrophil percentage and lower lymphocyte percentage than OAD cows on the high nutrition diet, whereas no difference in either variable was observed between cows milked OAD at either plane of nutrition, or between OAD and TAD cows on the low plane of nutrition. The reduction in milking frequency reduced milk yield and resulted in less mobilization of body reserves than when cows were milked more frequently, in agreement with previous studies (Andersen et al., 2003; O'Brien et al., 2005; Patton et al., 2006). Moreover, the combination of both a high plane of nutrition and TAD milking resulted in higher milk production in these cows compared with any other treatment. Thus, these cows were probably under more metabolic stress than animals in the other treatment combinations. These 2 factors combined with the normal period of periparturient immunosuppression (Mallard et al., 1998; Overton and Waldron, 2004) may have caused the resultant leukogram in the TAD cows. Nevertheless, although statistically different, the magnitude of differences between treatments was small, and all treatment means were within the normal range for cattle (Jain, 1993). Thus, the leukogram of cows milked twice daily at the high feed allowance cannot be considered a true stress leukogram. However, it is evident that these cows were under more metabolic pressure than cows on the other treatments, and that there was a slight shift in individual leukocyte percentages toward a leukogram that is associated with stress. Both of these results imply that utilizing management strategies to maximize milk production at the beginning of lactation increases stress and thus has the potential to impair cow welfare. It would be useful to carry out a long-term systems evaluation of once- versus twice-daily milking, so that the potential for and benefits of improved immune function could be compared with the cost of reduced milk yield.
Peripartum stress reduces eosinophil percentage (Holtenius et al., 2004; Feldman et al., 2006), which is in agreement with our results. Although milking frequency did not affect eosinophil percentage, cows on the high feed allowance had lower eosinophil percentage than those on the low feed allowance, both overall and during the first 2 sampling days postpartum. This difference could also be a result of increased metabolic stress associated with higher milk yields.

Our results regarding neutrophil percentage are not in complete agreement with previous studies. Keane et al. (2006) found that cows milked OAD had a higher expression of apoptosis regulatory genes, which led to slight neutrophilia compared with cows milked 3 times daily. However, as discussed earlier, Keane (2004) also found higher cortisol levels in ODM cows, which could have caused this result.

Milking frequency and feed allowance had different effects on leukocyte differentials. However, in both cases, cows exposed to treatments that could be expected to increase milk yield (i.e., the high feed allowance and TAD milking) expressed differential cell count patterns indicative of a slight impairment of the immune system compared with the other treatments. Thus, as hypothesized, management factors that minimize milk secretion appear to have a positive effect on immune system functionality, particularly at the beginning of lactation when milk yield increases rapidly. These results appear to contrast with the conclusions of Llamas Moya et al. (2008) and Keane et al. (2006), who hypothesized that increased milk accumulation in the udders of highyielding dairy cows milked once daily at the beginning of lactation could result in impaired immune function. However, Llamas Moya et al. (2008) found no effect of nutrition level on any variable measured, even though a high nutrition level is associated with higher udder firmness scores, whereas once a day milking does not have as great an effect (Gleeson et al., 2007; Tucker et al., 2007; O'Driscoll et al., 2010). Llamas Moya et al. (2008) did not find a significant effect of milking frequency on any of the parameters relating to monocyte functionality. A nutritional effect was only implicated as part of an interaction between nutrition level and milking frequency; monocytes from TAD cows on the low nutritional level had greater mean fluorescence intensity of oxidative burst following stimulation with phorbol 12-myristate 13-acetate (PMA) compared with those from TAD animals on the high nutritional level after PMA stimulation $(P<0.05)$. This result is actually in agreement with our hypothesis that cows that were less stimulated to produce milk had better immune function.

Llamas Moya et al. (2008) found that milking cows once daily at the beginning of lactation reduced the 
percentage of phagocytic neutrophils compared with milking twice daily, and concluded that this could be a result of physiological stress at the beginning of the lactation. However, we are unaware of any study that has found that once a day milking triggers a stress response associated with increased cortisol secretion, which is usually associated with physiological stress. The results from both studies appear contradictory; we found that cows milked once daily have a lower neutrophil percentage, whereas Llamas Moya et al. (2008) found that neutrophils from these cows were more functionally compromised than those of cows milked twice daily. Normally a reduced neutrophil percentage is associated with improvements in functionality (Burton et al., 2005). Further investigation of management procedures that minimize milk secretion and reduce mobilization of body reserves at the beginning of lactation could aid understanding of the mechanisms underlying these changes.

Evidence exists that multiparous cows have impaired immune function compared with primiparous cows (Mehrzad et al., 2002; Llamas Moya et al., 2008; Ohtsuka et al., 2009). With regard to leukocyte counts, our results are similar to those of Quiroz-Rocha et al. (2009), who investigated reference levels for hematological analytes of dairy cows around parturition, in that primiparous cows had lower eosinophil, higher lymphocyte, and similar monocyte levels to multiparous cows. In our study, multiparous cows experienced a period of slight neutrophilia and lymphopenia 2 to 3 wk postpartum compared with primiparous cows. Moreover, multiparous cows that were milked OAD had lower neutrophil percentage than those milked TAD, whereas neutrophil percentage in primiparous cows milked OAD or TAD did not differ, and neutrophil percentage of multiparous cows that were only milked OAD was similar to that of primiparous cows. This indicates that the higher milking frequency had more of an effect on multiparous than on primiparous cows. Multiparous cows produce more milk and lose more body condition in early lactation (Coffey et al., 2004; Bewley and Schutz, 2008) than primiparous cows, which places them at greater risk of metabolic stress. The application of a milking regimen that results in reduced milk secretion could ameliorate this risk.

Acute phase protein concentrations change in animals subjected to internal and external challenges, such as infection, inflammation, trauma, and stress (Baumann and Gauldie, 1994; Murata et al., 2004). The high SAA and $\mathrm{Hp}$ concentrations recorded at calving in this study were as expected, and the values at each sampling point were similar to those reported in previous studies $(\mathrm{Ny}-$ man et al., 2008; Huzzey et al., 2009; Olmos et al., 2009). Higher concentrations of $\mathrm{Hp}$ around calving are indicative of a well-functioning immune system, in particular with regard to udder health (Nyman et al., 2008). Contrarily, higher concentrations of $\mathrm{Hp}$ in later lactation occur when cows are, or have been, under metabolic stress, in particular during the transition period (Hiss et al., 2009). Although cows milked OAD had numerically higher Hp concentrations in the initial week postpartum compared with TAD cows, TAD cows had higher concentrations at the subsequent sampling points. This pattern of $\mathrm{Hp}$ concentration could thus be indicative of better immune status in OAD than TAD cows, again perhaps due to the greater metabolic stress in TAD cows. Although we found no interaction between parity status and sampling day, the higher Hp concentrations in primiparous cows were driven by a larger surge in Hp concentration in these cows than in multiparous animals at the $\mathrm{d} 1$ to 7 postpartum sampling time (unreported data). At other sampling times, Hp values were similar for both cohorts. Thus, these data are another indication of a superior immune status in primiparous animals.

Primiparous cows had a numerically higher SAA concentration than multiparous cows at the $\mathrm{d} 1$ to 7 postpartum sampling day, whereas values were similar at all other sampling days. Odensten et al. (2007) described how primiparous animals had higher SAA concentrations than multiparous cows during the dry period, and it is possible that this carried over to the first postpartum sampling point.

Both Con A and PHA are mitogens that are commonly used in immunological research to stimulate lymphocytes. Stimulation of lymphocytes to secrete antibodies and cytokines is often used to assess the functional activity of the immune system (Mallard et al., 1998). Interferon- $\gamma$ is a cytokine produced by activated T-lymphocytes and natural killer cells. A reduction of in vivo IFN- $\gamma$ production can occur in situations where an animal undergoes a period of stress or injury and is considered an indicator of immunosuppression (Fisher et al., 1997a; Earley and Crowe, 2002).

Cellular immune suppression has been reported in dairy cows that have low nutritional status during the peripartum period (Ohtsuka et al., 2006). This could explain the lower level of IFN- $\gamma$ production in TAD cows on LFA. Twice-a-day milking in combination with a low feed allowance is likely to have caused a longer period of negative energy balance in these cows than in the other treatments (Pomies and Remond, 2002).

Our finding that multiparous cows had higher levels of IFN- $\gamma$ production after Con A stimulation compared with primiparous cows is in agreement with previous literature (Lessard et al., 2004). Moreover, the suppression of IFN- $\gamma$ production around the time of calving was also expected (Lessard et al., 2003, 2004). Hap- 
toglobin has a suppressive effect on lymphocyte activity, and thus the higher Hp concentration reported in primiparous cows could also explain the lower IFN- $\gamma$ production in these animals (Murata and Miyamoto, 1993). However, although the response to Con A was suppressed in primiparous cows, IFN- $\gamma$ production did not differ between multiparous and primiparous animals after stimulation with PHA. This indicates that the lymphocyte response was not completely suppressed or could have been differentially suppressed. Indeed, Con $\mathrm{A}$ and PHA activate specific T-cell subpopulations in mice (Kirchner et al., 1980).

Unlike Loiselle et al. (2009), we found no effect of milking frequency on IFN- $\gamma$ production immediately postpartum. However, although that study found that cows milked once daily had higher IFN- $\gamma$ production at $\mathrm{d} 5$ and 14 postpartum, they found no effect on $\mathrm{d}$ 2,9 , or 21 . It is possible that any differences that were present in IFN- $\gamma$ production during our study were masked because samples were not taken on the same day postpartum for each cow.

\section{CONCLUSIONS}

The unavoidable period of immunosuppression that dairy cows experience during the peripartum period can be exacerbated or ameliorated by management factors. Our results indicate that cows subjected to management practices that reduced milk production (i.e., a low feed allowance or reduced milking frequency) had leukocyte differentials suggestive of improved immune function. These data are an important contribution to current knowledge about periparturient immunosuppression and imply that reducing the amount of metabolic stress at the beginning of lactation could have a slightly positive effect on immune system functioning.

\section{ACKNOWLEDGMENTS}

The authors gratefully acknowledge the assistance of Sean Arkins (Department of Life Science, University of Limerick, Limerick, Ireland) in designing the experiment. We also appreciate the skilled technical assistance of Tommy Condon (Animal and Grassland Innovation Centre, Teagasc, Moorepark, Fermoy, Co. Cork, Ireland) and thank the staff of the Animal and Grassland Research and Innovation Centre staff for the care of the experimental animals.

\section{REFERENCES}

Andersen, J. B., N. C. Friggens, K. Sejrsen, M. T. Sørensen, L. Munksgaard, and K. L. Ingvartsen. 2003. The effects of low vs. high concentrate level in the diet on performance in cows milked two or three times daily in early lactation. Livest. Prod. Sci. 81:119-128.
Baumann, H., and J. Gauldie. 1994. The acute phase response. Immunol. Today 15:74-80.

Bewley, J. M., and M. M. Schutz. 2008. Review: An interdisciplinary review of body condition scoring for cattle. Prof. Anim. Sci. 24:507-529.

Burton, J. L., S. A. Madsen, L.-C. Chang, P. S. D. Weber, K. R. Buckham, R. van Dorp, M.-C. Hickey, and B. Earley. 2005. Gene expression signatures in neutrophils exposed to glucocorticoids: A new paradigm to help explain "neutrophil dysfunction" in parturient dairy cows. Vet. Immunol. Immunopathol. 105:197-219.

Cairoli, F., M. Battocchio, M. C. Veronesi, D. Brambilla, F. Conserva, I. Eberini, R. Wait, and E. Gianazza. 2006. Serum protein pattern during cow pregnancy: Acute-phase proteins increase in the peripartum period. Electrophoresis 27:1617-1625.

Coffey, M. P., G. Simm, J. D. Oldham, W. G. Hill, and S. Brotherstone. 2004. Genotype and diet effects on energy balance in the first three lactations of dairy cows. J. Dairy Sci. 87:4318-4326.

Cole, D. J., A. J. Roussel, and M. S. Whitney. 1997. Interpreting a bovine CBC: Evaluating the leukon and acute-phase proteins. Vet. Med. 92:470-478.

Davis, S. R., V. C. Farr, and K. Stelwagen. 1999. Regulation of yield loss and milk composition during once-daily milking: A review. Livest. Prod. Sci. 59:77-94.

Earley, B., and M. A. Crowe. 2002. Effects of ketoprofen alone or in combination with local anesthesia during the castration of bull calves on plasma cortisol, immunological, and inflammatory responses. J. Anim. Sci. 80:1044-1052.

Fauci, A. S., and D. C. Dale. 1974. The effect of in vivo hydrocortisone on subpopulations of human lymphocytes. J. Clin. Invest. $53: 240-246$.

Feldman, B. F., J. G. Zinkl, and N. C. Jain. 2006. Schalm's Veterinary Haematology. 5th ed. Blackwell Publishing Professional, Ames, IA.

Fisher, A. D., M. A. Crowe, E. M. O'Nuallain, M. L. Monaghan, J. A. Larkin, P. O'Kiely, and W. J. Enright. 1997a. Effects of cortisol on in vitro interferon- $\gamma$ production, acute phase proteins, growth, and feed intake in a calf castration model. J. Anim. Sci. 75:1041-1047.

Fisher, A. D., M. A. Crowe, E. M. O'Nuallain, M. L. Monaghan, D. J. Prendiville, P. O'Kiely, and W. J. Enright. 1997b. Effects of suppressing cortisol following castration of bull calves on adrenocorticotropic hormone, in vitro interferon- $\gamma$ production, leukocytes, acute phase proteins, growth, and feed intake. J. Anim. Sci. 75:1899-1908.

Gleeson, D. E., B. O'Brien, L. Boyle, and B. Early. 2007. Effect of milking frequency and nutritional level on aspects of the health and welfare of dairy cows. Animal 1:125-132.

Herskin, M. S., L. Lunksgaard, and A.-M. Kristensen. 2003. Behavioural and adrenocortical responses of dairy cows toward novel food: Effects of food deprivation, milking frequency and energy density in the daily ration. Appl. Anim. Behav. Sci. 82:251-265.

Hiss, S., C. Weinkauf, S. Hachenberg, and H. Sauerwein. 2009. Short communication: Relationship between metabolic status and the milk concentrations of haptoglobin and lactoferrin in dairy cows during early lactation. J. Dairy Sci. 92:4439-4443.

Hoeben, D., E. Monfardini, G. Opsomer, C. Burvenich, H. Dosogne, A. DeKruif, and J. F. Beckers. 2000. Chemiluminescence of bovine polymorphonuclear leucocytes during the periparturient period and relation with metabolic markers and bovine pregnancy-associated glycoprotein. J. Dairy Res. 67:249-259.

Holtenius, K., K. Persson Waller, B. Essen-Gustavsson, P. Holtenius, and G. Hallen Sandgren. 2004. Metabolic parameters and blood leukocyte profiles in cows from herds with high or low mastitis incidence. Vet. J. 168:65-73.

Huzzey, J. M., T. F. Duffield, S. J. LeBlanc, D. M. Veira, D. M. Weary, and M. A. G. von Keyserlingk. 2009. Short communication: Haptoglobin as an early indicator of metritis. J. Dairy Sci. 92:621-625.

Jain, N. C. 1993. Essentials of Veterinary Hematology. Lea \& Febiger, Philadelphia, PA.

Keane, C. J., A. J. Hanlon, J. F. Roche, J. L. Burton, J. F. Mee, J. V. O'Doherty, and T. Sweeney. 2006. Short communication: A potential antiapoptotic phenotype in neutrophils of cows milked once daily in early lactation. J. Dairy Sci. 89:1024-1027. 
Keane, C. J. 2004. An investigation into the effect of metabolic status on the health and welfare of dairy cows. $\mathrm{PhD}$ Thesis. University College Dublin, Ireland.

Kennedy, E., M. O'Donovan, F. P. O'Mara, J. P. Murphy, and L. Delaby. 2007. The effect of early-lactation feeding strategy on the lactation performance of spring-calving dairy cows. J. Dairy Sci. 90:3060-3070.

Kirchner, H., H. Fenkl, R. Zawatzky, H. Engler, and H. Becker. 1980. Dissociation between interferon production induced by phytohemagglutinin and concanavalin A in spleen cell cultures of nude mice. Eur. J. Immunol. 10:224-225.

Lacetera, N., U. Bernabucci, D. Scalia, B. Ronchi, G. Kuzminsky, and A. Nardone. 2005. Lymphocyte function in dairy cows in hot environment. Int. J. Biometeorol. 50:105-110.

Lacetera, N., D. Scalia, O. Franci, U. Bernabucci, B. Ronchi, and A. Nardone. 2004. Effects of nonesterified fatty acids on lymphocyte function in dairy heifers. J. Dairy Sci. 87:1012-1014.

Lessard, M., N. Gagnon, D. L. Godson, and H. V. Petit. 2004. Influence of parturition and diets enriched in n- 3 or n- 6 polyunsaturated fatty acids on immune response of dairy cows during the transition period. J. Dairy Sci. 87:2197-2210.

Lessard, M., N. Gagnon, and H. V. Petit. 2003. Immune response of postpartum dairy cows fed flaxseed. J. Dairy Sci. 86:2647-2657.

Llamas Moya, S., M. Alonso Gomez, L. A. Boyle, J. F. Mee, B. O'Brien, and S. Arkins. 2008. Effects of milking frequency on phagocytosis and oxidative burst activity of phagocytes from primiparous and multiparous diary cows during early lactation. J. Dairy Sci. 91:587-595.

Loiselle, M. C., C. Ster, B. G. Talbot, X. Zhao, G. F. Wagner, Y R. Boisclair, and P. Lacasse. 2009. Impact of postpartum milking frequency on the immune system and the blood metabolite concentration of dairy cows. J. Dairy Sci. 92:1900-1912.

Lowman, B. G., N. Scott, and S. Somerville. 1976. Condition Scoring of Cattle. Rev. ed. Bulletin no. 6. East of Scotland College of Agriculture, Edinburgh, UK.

Madsen, S. A., P. S. D. Weber, and J. L. Burton. 2002. Altered expression of cellular genes in neutrophils of periparturient dairy cows. Vet. Immunol. Immunopathol. 86:159-175.

Mallard, B. A., J. C. Dekkers, M. J. Ireland, K. E. Leslie, S. Sharif, C. Lacey Vankampen, L. Wagter, and B. N. Wilkie. 1998. Alteration in immune responsiveness during the peripartum period and its ramification on dairy cow and calf health. J. Dairy Sci. 81:585-595

McNamara, S., J. J. Murphy, F. P. O'Mara, M. Rath, and J. F. Mee. 2008. Effect of milking frequency in early lactation on energy metabolism, milk production and reproductive performance of dairy cows. Livest. Sci. 117:70-78

Mehrzad, J., L. Duchateau, S. Pyorala, and C. Burvenich. 2002. Blood and milk neutrophil chemiluminescence and viability in primiparous and multiparous dairy cows during late pregnancy, around parturition and early lactation. J. Dairy Sci. 85:3268-3276.

Murata, H., and T. Miyamoto. 1993. Bovine haptoglobin as a possible immunomodulator in the sera of transported calves. Br. Vet. J. 149:277-283.

Murata, H., N. Shimada, and M. Yoshioka. 2004. Current research on acute phase proteins in veterinary diagnosis: An overview. Vet. J. $168: 28-40$

Nyman, A.-K., U. Emanuelson, K. Holtenius, K. L. Ingvartsen, T. Larsen, and K. Persson Waller. 2008. Metabolites and immune variables associated with somatic cell counts of primiparous dairy cows. J. Dairy Sci. 91:2996-3009.

O'Brien, B., D. Gleeson, and J. Mee. 2005. Effect of milking frequency and feeding level on milk production, somatic cell count and reproductive performance of dairy cows over the first 20 weeks of lactation. Proceedings of the Agricultural Research Forum, Tullamore, Co. Offaly, Ireland. Standard Printers, Galway, Ireland.

O'Driscoll, K., D. Gleeson, B. O'Brien, and L. Boyle. 2011. Does omission of a regular milking event affect cow comfort? Livest. Sci. 138:132-143.
O'Driscoll, K., B. O'Brien, D. Gleeson, and L. Boyle. 2010. Effect of milking frequency and nutritional level on hoof health, locomotion score and lying behaviour of dairy cows. Livest. Sci. 127:248-256.

Odensten, M. O., K. Holtenius, and K. Persson Waller. 2007. Effects of two different feeding strategies during dry-off on certain health aspects of dairy cows. J. Dairy Sci. 90:898-907.

Ohtsuka, H., M. Uematsu, Y. Saruyama, M. Ono, M. Kihiruimaki, T. Ando, and S. Kawamura. 2009. Age-related alterations in peripheral leukocyte population of healthy Holstein dairy cows during the pre-calving period. J. Vet. Med. Sci. 71:1121-1124.

Ohtsuka, H., C. Watanabe, M. Kohiruimaki, T. Ando, D. Watanabe, M. Masui, T. Hayashi, R. Abe, M. Koiwa, S. Sato, and S. Kawamura. 2006. Comparison of two different nutritive conditions against the changes in peripheral blood mononuclear cells of periparturient dairy cows. J. Vet. Med. Sci. 68:1161-1166.

Olmos, G., L. Boyle, B. Horan, D. P. Berry, R. Sayers, A. Hanlon, and J. F. Mee. 2009. Effect of Holstein-Friesian genetic group on peripartum and early lactation haematological and acute phase protein profiles, health and fertility. Animal 3:1013-1024.

Overton, T. R. and M. R. Waldron. 2004. Nutritional management of transition dairy cows: Strategies to optimise metabolic health. J. Dairy Sci. 87:E105-E119.

Patel, O. V., T. Takahashi, N. Takenouchi, M. Hirako, N. Sasaki, and I. Domekis. 1996. Peripheral cortisol levels throughout gestation in the cow: Effect of stage of gestation and foetal number. Br. Vet. J. $152: 425-432$

Patton, J., D. A. Kenny, J. F. Mee, F. P. O’Mara, D. C. Wathes, M Cook, and J. J. Murphy. 2006. Effect of milking frequency and diet on milk production, energy balance, and reproduction in dairy cows. J. Dairy Sci. 89:1478-1487.

Pomies, D., and B. Remond. 2002. Once a day milking of dairy cows during the whole lactation: Consequences on performance and milk quality. Pages 195-198 in 9emes Rencontres autour des recherches sur les ruminants. INRA, Paris, France.

Quiroz-Rocha, G. F., S. J. LeBlanc, T. F. Duffield, D. Wood, K. E. Leslie, and R. M. Jacobs. 2009. Reference limits for biochemical and haematological analytes of dairy cows one week before and one week after parturition. Can. Vet. J. 50:383-388.

Rothel, J. S., S. L. Jones, L. A. Corner, J. C. Cox, and P. R. Wood 1990. A sandwich enzyme immunoassay for bovine interferon-gamma and its use for detection of tuberculosis in cattle. Aust. Vet. J. $67: 134-137$.

Schlamberger, G., S. Wiedemann, E. Viturro, H. H. D. Meyer, and M. Kaske. 2010. Effects of continuous milking during the dry period or once daily milking in the first 4 weeks of lactation on metabolism and productivity of dairy cows. J. Dairy Sci. 93:2471-2485.

Shayanfar, F., H. H. Head, C. J. Wilcox, and W. W. Thatcher. 1975. Adrenal responses in lactating Holstein cows. J. Dairy Sci. 58:870-878.

Suriyasathaporn, W., C. Heuer, E. N. Noordhuizen-Stassen, and Y. H. Schukken. 2000. Hyperketonemia and the impairment of udder defense: A review. Vet. Res. 31:397-412.

Thun, R., E. Eggenberger, K. Zerobin, T. Luscher, and W. Vetter. 1981. Twenty-four hour secretory pattern of cortisol in the bull: Evidence of episodic secretion and circadian rhythms. Endocrinology 109:2208-2212.

Ting, S. T. L., B. Earley, and M. A. Crowe. 2003. Effect of repeated ketoprofen administration during surgical castration of bulls on cortisol, immunological functions, feed intake, growth, and behaviour. J. Anim. Sci. 81:1253-1264.

Tucker, C. B., D. E. Dalley, J.-L. K. Burke, and D. A. Clark. 2007. Milking cows once daily influences behavior and udder firmness at peak and mid lactation. J. Dairy Sci. 90:1692-1703.

Urban, B., and J. P. Caudal. 1990. Herbometre automatise. Pages 5759 in INRA Dept Informatique. Les journées de la mesure. Electronique, informatique, automatique. INRA, Port Leucate, France.

Venkataseshu, G. K., and V. L. Estergreen Jr. 1970. Cortisol and corticosterone in bovine plasma and the effect of adrenocorticotrophin. J. Dairy Sci. 53:480-483. 